\title{
ANALISIS PENGEMBANGAN BISNIS TOKO LAST SNEAKERS DENGAN PENDEKATAN BUSINESS MODEL CANVAS MENGGUNAKAN SEARCH ENGINE OPTIMAZATION
}

\author{
Alvionita Desiana ${ }^{1)}$, Samsinar ${ }^{2)}$ \\ ${ }^{1}$ Sistem Informasi, Fakultas Teknologi Informasi, Universitas Budi Luhur \\ ${ }^{1,2} \mathrm{JI}$. Raya Ciledug, Petukangan Utara, Kebayoran Lama, Jakarta Selatan 12260 \\ E-mail : alvionitadesiana93@gmail.com ${ }^{11}$, samsinar@budiluhur.ac.id ${ }^{22}$
}

\begin{abstract}
Abstrak
Internet merupakan salah satu kunci utama yang menghubungkan jaringan komputer satu ke komputer lainnya secara mendunia. Kurangnya perkembangan teknologi yang terdapat pada Toko Last Sneakers mengakibatkan kurang terkenal dikalangan masyarakat. Cara Toko Last Sneakers mempromosikan tokonya kepada masyarakat masih sederhana sehingga masyarakat kurang mengenal toko tersebut. Kehadiran e-commerce sebagai media transaksi baru ini tentunya menguntungkan banyak pihak, baik pihak customer maupun pihak produsen dan penjual. Untuk itu Toko Last Sneakers mulai mencari terobosan baru dengan menggunakan e-commerce sebagai salah satu media promosi dan penjualan untuk meningkatkan omzet penjualan serta pemasarannya tidak terbatas namun dapat diketahui oleh banyak masyarakat. Tujuan dari penulisan ini adalah membuat suatu media website e-commerce pada Toko Last Sneakers untuk memudahkan customer untuk melakukan pembelian tanpa harus datang langsung ke toko. Metode yang digunakan adalah Business Model Canvas yang akan digunakan untuk menggambarkan model bisnis Toko Last Sneakers. Hasil dari penelitian ini adalah website yang dijadikan sebagai media promosi dan mempermudah proses penjualan yang dilakukan secara online.
\end{abstract}

Kata kunci: E-commerce, Business Model Canvas, Website, Sneakers.

\section{PENDAHULUAN}

Toko Last Sneakers merupakan toko yang menjual berbagai macam sneakers. Cara toko mempromosikannya hanya melalui brosur yang mengakibatkan masyarakat kurang mengenal toko dan produk tersebut. Maka dari itu penulis ingin membuat media informasi yang bertujuan agar toko tersebut dapat dikenal oleh banyak kalangan masyarakat, yaitu dengan membangun e-commerce, serta digunakan untuk menyampaikan informasi secara langsung dengan elemen masyarakat yang membutuhkan barang-barang tersebut. E-commerce merupakan jual beli barang atau jasa melalui sistem elektronik berupa internet tanpa harus bertemu langsung dengan customer dan penjual [1].

Tentunya sebelum memulai suatu bisnis maka harus ada gambaran bisnis itu akan menjadi seperti apa, maka dari itu Toko Last Sneakers membuat business model canvas agar bisnis tersebut bisa lebih berstruktur. Business Model Canvas merupakan kerangka kerja sebelum memulai suatu bisnis yang dibuat melalui kanvas atau lukisan sehingga dapat dipahami dan dimengerti [2] .

Berdasarkan hasil analisa serta pengumpulan data yang dilakukan, maka ditemukan permasalahan yang dihadapi dalam proses penjualan, salah satunya yaitu stok produk lama tidak terjual, mengakibatkan stok produk lama tersimpan di gudang. Tujuan dan manfaat dari penulisan penelitian ini diharapkan agar volume penjualan dapat meningkat, lebih mudah dalam mencari informasi produk dan jumlah pelanggan dapat meningkat.

Penelitian pertama yang juga sudah dilakukan sebelumnya oleh [3] mengalami kesulitan untuk mengembangkan produknya dan masih kurangnya media penyampaian mengenai informasi produknya dikarenakan media yang digunakan untuk mempromosikan hanya menggunakan instagram, berbeda dengan kompetitor lain yang sudah menggunakan website untuk mempromosikannya. Penelitian yang dilakukan oleh [4] sudah online akan tetapi tidak efesien jika media promosinya belum menggunakan Search Engine Optimazation (SEO). Penelitian yang dilakukan oleh [5] pada toko Winata ini, penjualan biasanya dilakukan secara langsung dan bertatap muka dengan konsumen.

Maka dari itu alasan penulis menggunakan metode Business Model Canvas adalah agar lebih efektif untuk membuat perencanaan bisnis dan meningkatkan skala bisnis toko tersebut agar lebih besar.

\section{METODE PENELITIAN}

\subsection{Kerangka Pemikiran}

Berdasarkan kerangka pemikiran yang telah digambarkan pada gambar 1. dapat diuraikan masing-masing tahap dalam penelitian sebagai berikut : 


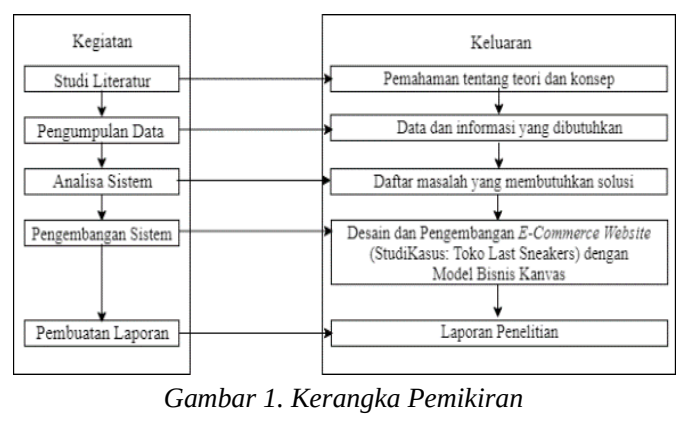

a. Studi Literatur

Tahap ini dilakukan untuk mencari landasanlandasan teori yang diperoleh dari berbagai jurnal maupun internet untuk melengkapi konsep-konsep sehingga memiliki landasan yang baik dan sesuai.

b. Pengumpulan Data

Pada tahap ini peneliti mengumpulkan beberapa data melalui wawancara dan observasi agar dapat dilakukan analisis dan pengamatan terhadap proses bisnis yang sedang berjalan pada sistem Toko Last Sneakers, untuk mendapatkan informasi yang dibutukan.

c. Analisis Sistem

Tahap ini dilakukan identifikasi masalah yang terjadi pada Toko Last Sneakers. Diharapkan peneliti mendapatkan kendala atau masalah-masalah yang terjadi di toko tersebut sehingga peneliti dapat mencari solusi dari masalah tersebut.

d. Pengembangan Sistem

Tahap ini penulis mengembangkan sistem dengan menggunakan metode Business Model Canvas agar lebih efektif untuk membuat perencanaan bisnis dan meningkatkan skala bisnis toko tersebut agar lebih besar.

e. Pembuatan Laporan

Pada tahap ini penulis melakukan pembuatan laporan yang disusun sesuai hasil penelitian. Salah satu laporannya berupa laporan penjualan, laporan pembayaran, laporan pengiriman, laporan stok barang, laporan pengembalian produk, laporan produk terlaris.

\subsection{Metodologi Analisis}

Pada pembuatan E-Commerce ini, penulis menggunakan metode Business Modeling Canvas untuk mengevaluasikan model bisnis yang diterapkan pada Toko Last Sneakers memungkinkan kita untuk menggambar atau mendesain toko tersebut untuk membuat strategi bisnis yang sudah ada agar menjadi lebih berkembang. Teknik analisis ini digunakan untuk menerjemahkan model bisnis dari objek penelitian Toko Last Sneakers dengan data yang didapatkan berdasarkan hasil wawancara. Selain menggunakan teknik wawancara dari analisis ini juga didapatkan dari hasil pengumpulan data-data dan hasil dokumentasi yang informasi tersebut akan dikumpulkan dan digolongkan berdasarkan poinpoin dari Business Modeling Canvas.

\section{HASIL DAN PEMBAHASAN}

\subsection{Business Model Canvas}

Penerapan pada business model canvas adalah tahapan awal sebelum memulai suatu usaha atau bisnis yang bertujuan untuk menjelaskan elemenelemen penting yang terdapat didalam suatu bisnis [2].

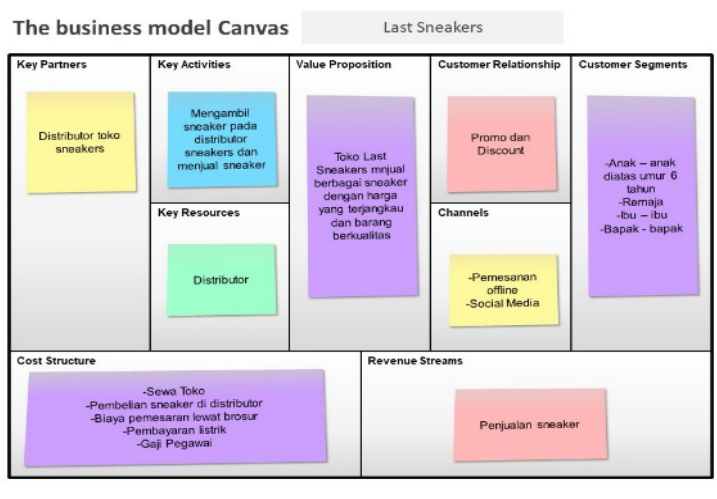

Gambar 2. Business Model Canvas

Pada gambar 2. yang telah digambarkan, maka berikut masing-masing deskripsi :

a. Customer Segment

Customer Segment adalah calon pembeli atau customer yang akan membeli produk kita atau target market kita. Pada Toko Last Sneakers target market yang ingin ditentukan adalah anak-anak diatas umur 6 tahun, remaja, ibu-ibu dan bapak-bapak.

b. Value Proposition

Pada Toko Last Sneakers value proposition adalah menjual berbagai macam sneakers dengan harga yang terjangkau dan barangnya sangat berkualitas.

c. Channel

Produk pada Toko Last Sneakers dijualkan melalui instagram, bukalapak, shopee, tokopedia atau bisa juga dibeli langsung ditokonya yang berada di Jl. Masjid Cidodol belakang SMPN 153 Jakarta.

d. Customer Relationship

Pada Toko Last Sneakers customer relationship nya adalah dengan mengadakan promo setiap pembelian satu sneaker mendapatkan gratis satu kaos atau topi sehingga customer nantinya akan puas dan datang kembali untuk membeli lagi produk dari toko tersebut.

e. Revenue System

Toko Last Sneakers menghasilkan pendapatan dari hasil penjualan sneakers terhadap customer.

f. Key Activities

Cara penjual mendapatkan key activities pada

Toko Last Sneakers adalah dengan mencari 
distributor toko sneaker yang bagus dan berkualitas dengan harga yang terjangkau.

\section{g. Key Resource}

Kekuatan yang terdapat pada toko Last Sneakers adalah distributor, karena jika tidak ada distributor toko tersebut tidak akan bisa melakukan penjualan. Distributor yang dipilih oleh penjual merupakan distributor yang memiliki bahan sneakers yang bagus dan berkualitas.

h. Key Partnership

Distributor merupakan partner kerjasama yang dimiliki oleh Toko Last Sneakers karena jika tidak ada distributor tersebut maka tidak akan berjalannya bisnis ini.

\section{i. Cost Structure}

Biaya yang dikeluarkan oleh Toko Last Sneakers adalah sewa toko, pembelian sneakers di distributor, biaya pemasaran lewat brosur, pembayaran listrik dan pembayaran gaji pegawai.

\subsection{Sistem Usulan}

a. Proses Pemesanan Produk

Pada gambar 3. customer masuk ke halaman website, lalu login dengan memasukan email dan password yang telah dibuat pada saat registrasi. Jika berhasil melakukan login maka customer dialihkan ke halaman member area. Setelah itu memilih menu shop untuk membeli produk yang ingin dibeli, lalu pilih produk yang diinginkan. Kemudian klik tombol order now, setelah itu pilih ukuran yang diinginkan dan klik tombol quantity untuk jumlah produk yang ingin dibeli, lalu ketika semuanya sudah diisi maka klik tombol add to cart lalu muncul konfirmasi pembayaran. Customer masuk ke cart setelah itu customer mengisi form alamat yang ingin dikirim jika form sudah diisi semua maka muncul total harga dan ongkir lalu klik tombol checkout. Setelah itu muncul konfirmasi checkout dan jika berhasil maka akan ada notifikasi di member area.

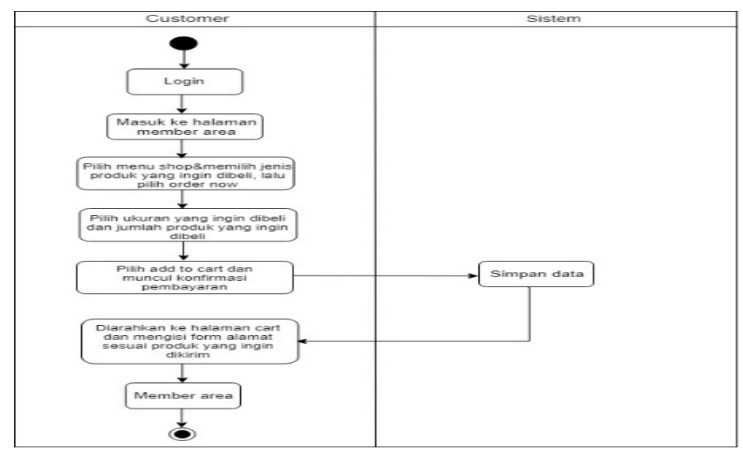

Gambar 3. Activity Diagram Pemesanan Produk

b. Proses Konfirmasi Pembayaran

Pada gambar 4. customer masuk ke website, lalu login dengan memasukkan email dan password. Jika berhasil customer dialihkan ke halaman member area, setelah itu customer pilih konfirmasi pembayaran. Lalu customer menginput kode pesanan yang terdapat di pesanan saya dan setelah diinput kode pesanan maka akan otomatis muncul total harga, setelah itu customer memilih bank yang ingin dituju untuk melakukan pembayaran. Kemudian customer mengupload bukti transfer yang sudah dibayar, jika semuanya sudah diisi maka klik tombol send. Dan jika berhasil maka muncul tulisan "success", tetapi jika salah maka akan muncul tulisan "kode pesanan tidak valid". Setelah itu admin mengecek pembayaran jika customer itu sudah melakukan konfirmasi pembayaran maka admin mengubah status pembayaran menjadi proses.

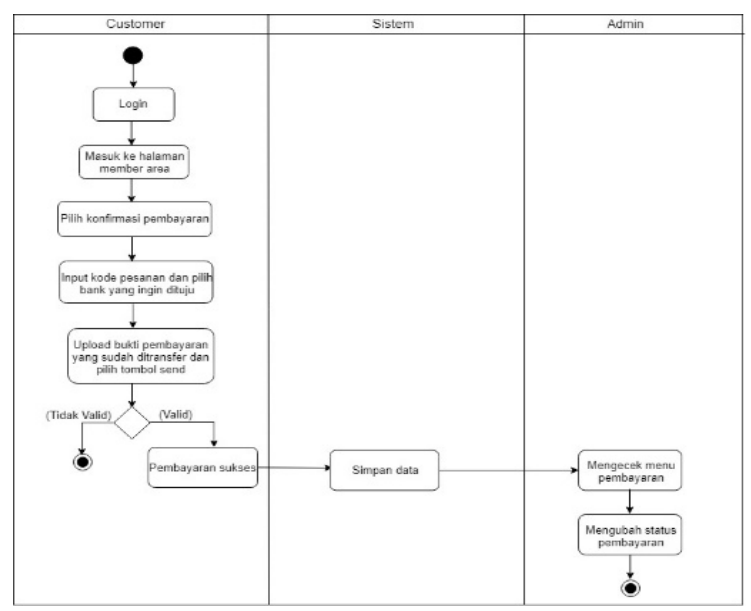

Gambar 4. Activity Diagram Konfirmasi Pembayaran

\section{c. Proses Pengiriman}

Pada gambar 5. admin mengirim produk yang telah dipesan oleh customer kepada pihak ketiga yaitu ekspedisi sesuai dengan alamat yang dipesan. Setelah itu admin menerima no resi dari ekpedisi dan admin melakukan input no resi pada menu pengiriman di website, jika sudah admin mengubah status menjadi delivery. Lalu customer akan menerima no resi yang telah diberikan oleh admin.

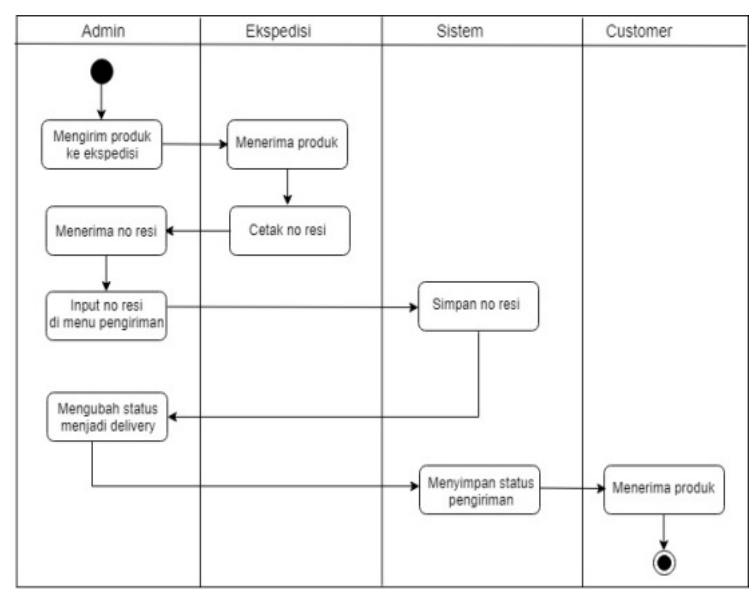

Gambar 5. Activity Diagram Pengiriman 


\subsection{Use Case Diagram}

Pada Toko Last Sneakers terdapat use case diagram yang bertujuan untuk mendeskripsikan antara actor dan sistem yang akan dibuat [6].

a. Use Case Login

Pada gambar 6 terdapat actor admin dan customer baru untuk melakukan login sebelum masuk ke halaman website.

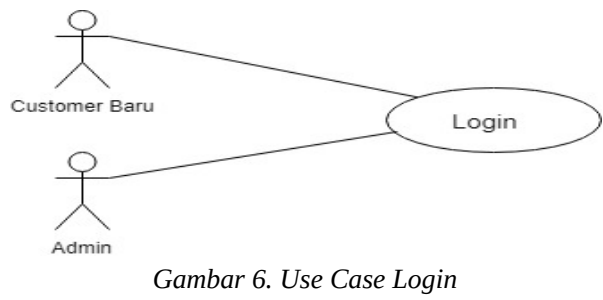

b. Use Case Master

Pada gambar 7. terdapat actor admin untuk menginput kategori produk, produk, kategori blog dan blog.

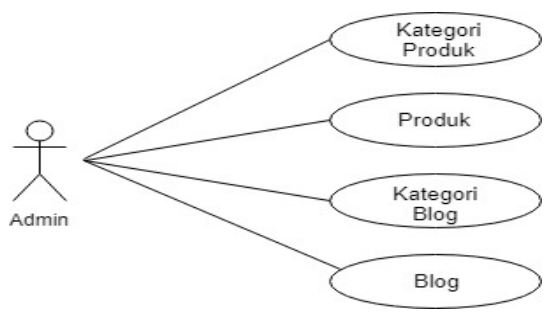

Gambar 7. Use Case Master

c. Use Case Transaksi

Pada gambar 8. terdapat actor customer dan admini. Customer menginput pesanan yang ingin dibeli setelah itu masuk ke dalam keranjang belanja dan masuk ke dalam check out lalu customer melakukan konfirmasi pembayaran, jika sudah maka admin melakukan ganti status dan menginput no resi.

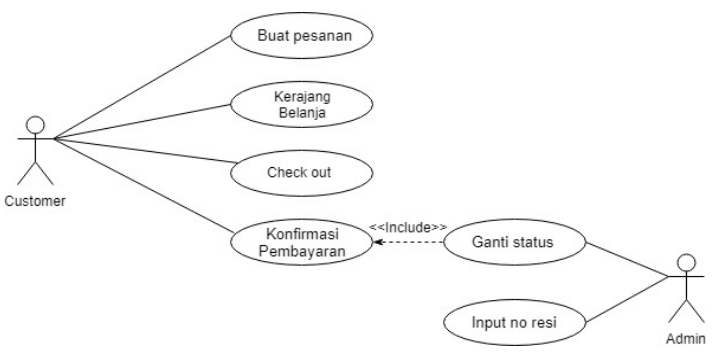

Gambar 8. Use Case Master Transaksi

d. Use Case Laporan

Pada gambar 9. terdapat actor admin dan pemilik. Admin menginput laporan penjualan, laporan pembayaran, laporan pengiriman, laporan stok barang, laporan pengembalian produk, laporan produk terlaris setelah itu diberikan kepada pemilik.

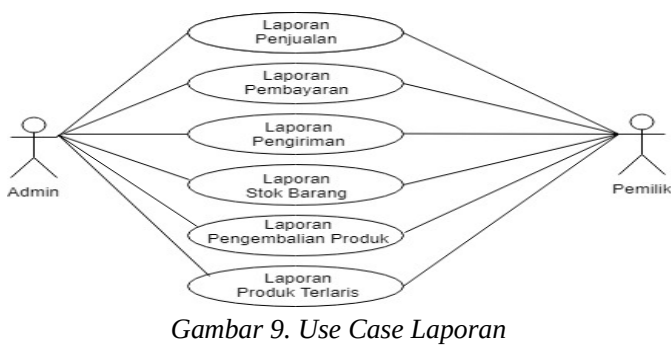

\subsection{Class Diagram}

Pada gambar 10. merupakan class diagram yang terdapat pada website Toko Last Sneakers.

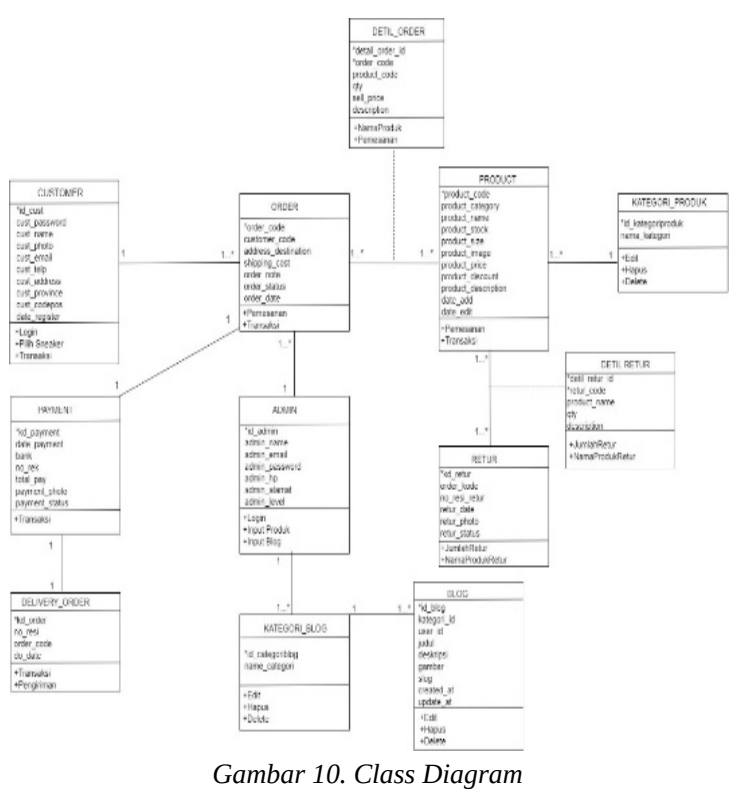

\subsection{Rancangan Layar (User Interface)}

Berikut ini beberapa rancangan layar pada website Toko Last Sneakers:

a. Registrasi Customer

Pada gambar 11. adalah rancangan layar regostrasi customer untuk menampilkan form data diri yang akan diisi oleh customer baru.

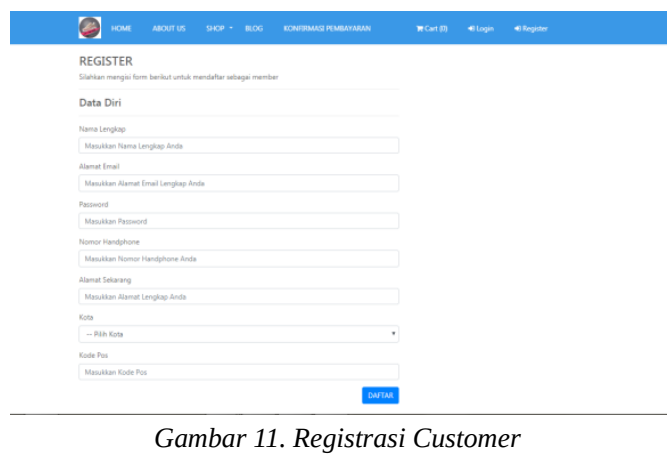

b. Login Customer 
Pada gambar 12. merupakan login customer yang menampilkan data diri customer yang telah diisi.

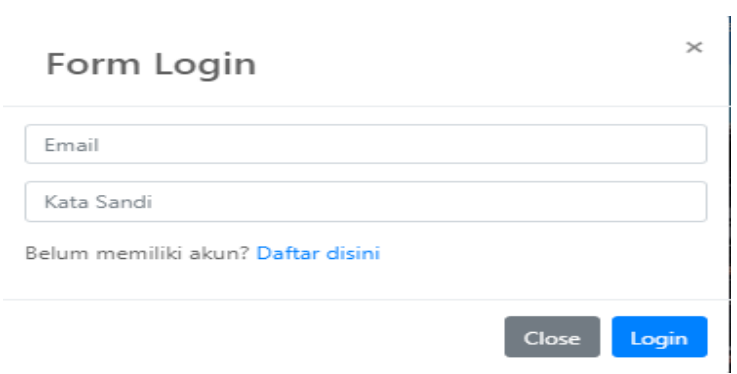

Gambar 12. Login Customer

c. Input Pesanan

Pada gambar 13. adalah cara bagaiman customer melakukan pesanan yang ingin dibeli.

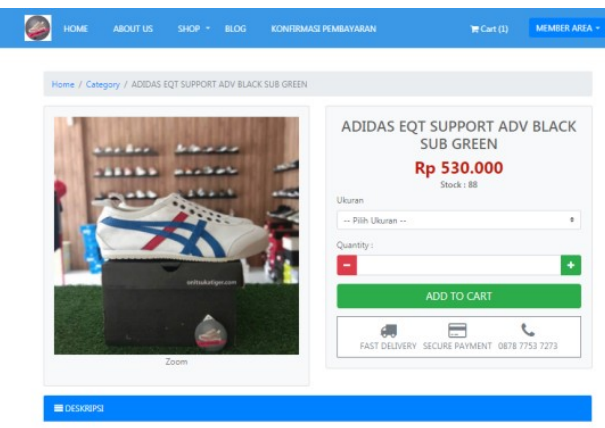

Gambar 13. Input Pesanan

3.6. SEO

Teknik SEO adalah teknik yang digunakan untuk memudahkan website agar dengan mudah ditemukan pada saat melakukan pencaharian di mesin pencari [4].

\section{a. Strategi $S E O$}

Berikut ini adalah cara strategi SEO pada website Last Sneakers:

1) Meta description dan keyword

Agar website mendapatkan peringkat pertama di mesin pencarian, maka harus membuat meta tag. Meta Tag adalah suatu kode HTML yang bertujuan untuk memudahkan mencari rangkuman isi dari website.

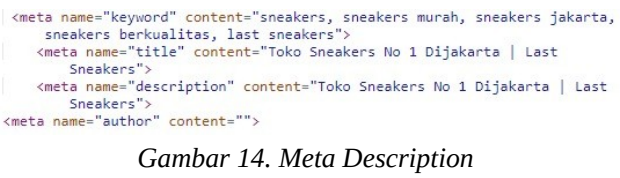

\section{2) Tag Title}

Penempatan tag title pada umunya dibawah tag “<head >”. Dibawah ini merupakan tampilan tag title yang mengandung keyword yang sesuai dengan website.

〈title>Toko Sneakers № 1 Dijakarta | Last Sneakersk/title> Gambar 15. Tag Title

\section{b. Uji Coba SEO}

1) Uji dengan Google Analytic

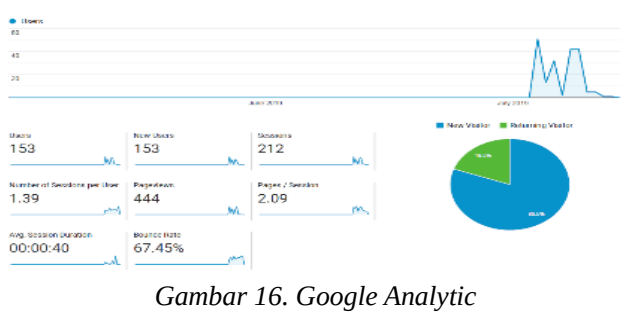

2) Uji dengan Mesin Pencari

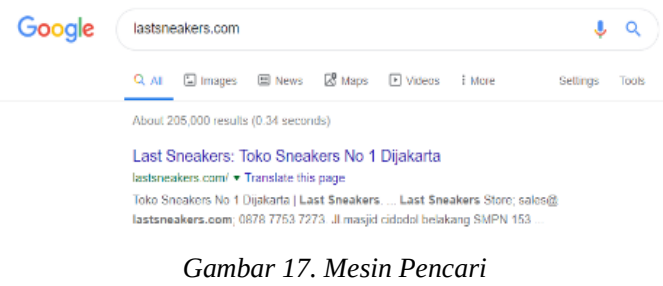

c. Marketing

Pada toko Last Sneakers marketing pemasaran dengan cara menjual produknya melalui instagram.

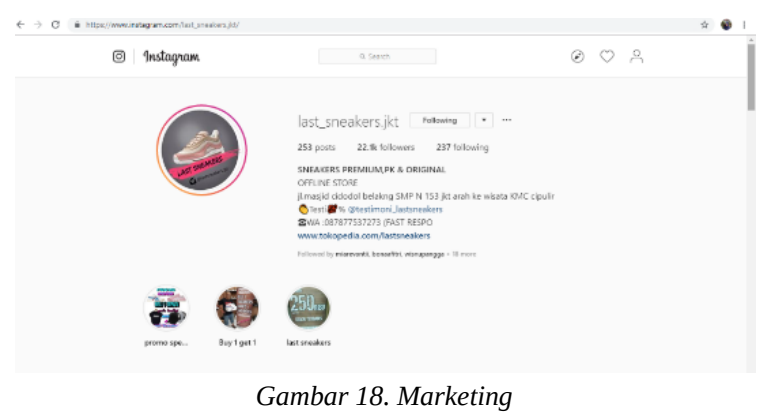

\section{KESIMPULAN}

Kesimpulan yang dapat diambil dari penyusunan penelitian ini adalah sebagai berikut:

1) Dengan adanya data yang sudah tersimpan di dalam database maka proses pembuatan laporan lebih cepat dan akurat setiap bulannya.

2) Mempermudah dalam memasarkan stok produk lama sehingga produk lama dapat terjual.

3) Dengan adanya website ini maka harga produk sudah ditetapkan sehingga customer tidak dapat menurunkan harga yang sudah tertera.

4) Mempermudah customer dalam melakukan pemesanan tanpa harus datang ke toko. 


\section{DAFTAR PUSTAKA}

[1] Heru, Shabur, Susilo. Implementasi E-Commerce Sebagai Media Penjualan Online (Studi Kasus PAda Toko Pastbrik Kota Malang), Jurnal Administrasi Bisnis, Vol.29(1), 2015, pp.1-9.

[2] Pratami dan Wijaya. Penerapan Bisnis Model Kanvas Dalam Penentuan Rencana Manajemen Usaha Jasa Pengiriman Dokumen Di Denpasar. Jurnal Sistem dan Informatika, Vol.11(1), 2016, pp.77-85.

[3] Sijabat dan Theresia. Perancangan Model Bisnis UKM Atelier Prana Dengan Menggunakan Pendekatan Business Model Canvas, e-Procceding of Engineering, Vol.5(3), 2018, pp.6828-6833, ISSN 2355-9365

[4] Hayaty, Mardhiya, Meylasari, Dwi. Implementasi Website Berbasis Search Engine Optimization (SEO) Sebagai Media Promosi, Jurnal Informatika (JI) UBSI, Vol.5(2), 2018, pp.295-300, ISSN 23556579.

[5] Suryanto, Pattiasina dan Soetarmono. Perancangan dan Pengembangan Toko Online dengan Metode Interaction Flow Modeling Language (Studi Kasus Toko Winata). Jurnal Teknika, Vol.6(1), 2017, pp.718, ISSN 2549-8037

[6] Ariefni dan Legowo. Penerapan Konsep Monitoring Dan Evaluasi Dalam Sistem Informasi Kegiatan Mahasiswa Di Perbanas Institute Jakarta. Jurnal Teknik Informatika dan Sistem Informasi. Vol.4(3), 2018, pp.422-432, ISSN 2443-2210. 